\title{
An Easy to Miss, but Preventable Tragedy: Vasa Previa
}

\author{
Catarina Reis-de-Carvalho ${ }^{1,2}$ Maria Afonso ${ }^{1 \odot}$ Rui Marques Carvalho ${ }^{1 \odot}$
}

${ }^{1}$ Department of Obstetrics, Gynaecology and Reproductive Medicine, Centro Hospitalar Universitário Lisboa Norte, Lisbon, Portugal

2 Faculty of Medicine, Universidade de Lisboa, Lisbon, Portugal

Address for correspondence Catarina Reis de Carvalho, MD, Av. Prof. Egas Moniz MB, Lisboa, 1649-028, Portugal

Rev Bras Ginecol Obstet 2020;42(8):508-510.

\section{Dear Editor,}

The role of renowned scientific journals, like yours, is to bring innovation, but also education. And so, we decided to bring to your attention a condition that is rare, but still frequent enough to be known to all obstetrician-gynecologists. It is in our hands this simple diagnosis that can prevent an obstetric tragedy.

Vasa previa is defined as the presence of aberrant fetal vessels running within the membranes near the internal os of the cervix as a result of abnormal placentation. ${ }^{1}$ There are two types, depending on if the free vessel is connected to a velamentous cord (type I) or connected to a succenturiate or accessory lobe of the main placenta (type II). ${ }^{2}$ The estimated incidence is 1 in 2,500 deliveries, but it is much higher ( 1 in 700 births) among patients who conceive through assisted reproductive technologies. Most cases (85\%) have $\geq 1$ identifiable risk factors, including in-vitro fertilization, multiple gestations, bilobed, succenturiate or low-lying placentas, and velamentous cord insertion. ${ }^{3}$

When the condition is not diagnosed antenatally, the perinatal mortality rate is reported to be $\sim 44 \%{ }^{3}$ If an emergency cesarean delivery is required, and if the diagnosis of vasa previa is not made in the antenatal period, $<50 \%$ of neonates survive. ${ }^{4}$

There is much controversy regarding the screening of vasa previa. Most authors do not recommend universal screening. ${ }^{5}$ However, there is a consensus that all cases with recognized risk factors should be routinely screened, ideally around mid-gestation (18-26 weeks), through transvaginal ultrasound with color Doppler imaging (CDI). ${ }^{1}$ Ruiter et $\mathrm{al}^{5}$ identified a median prenatal detection rate of $93 \%$ and a specificity of $99 \%$ when this approach is taken. Nevertheless, some precautions must be considered to rule out a diagnosis of a pseudo vasa previa, namely, confirm the placental cord insertion and reject the presence of a space between the placental vessels and the internal os. ${ }^{6}$

The optimal surveillance strategy in the case of vasa previa, including the need for antepartum hospitalization, is not welldefined. International guidelines recommended a scheduled cesarean section of all asymptomatic women presenting with vasa previa between 34 and 36 weeks of gestation. ${ }^{2}$

To illustrate this condition, we would like to portray a case of a 32-year-old primiparous pregnant woman with a diagnosis of anterior low-lying placenta on her routine transabdominal ultrasound at 28 weeks of pregnancy. A transvaginal ultrasound measured a distance of the placen-

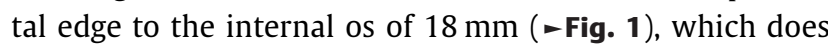
not prevent a vaginal delivery. However, the complementary study with the use of $\mathrm{CDI}$ allowed the observation of a posterior placental cotyledon (placenta succenturiata), that was $1.5 \mathrm{~mm}$ from the internal os, with vessels connecting the two parts of the placenta, running over the internal os (vasa previa) (-Fig. 2). Moreover, we found a short cervix with $19 \mathrm{~mm}$ of length. Some authors have suggested that there is a relation between a cervical length of $\leq 30 \mathrm{~mm}$, or $\leq 25 \mathrm{~mm}$ in other studies, and higher rates of antepartum bleeding requiring emergency delivery. ${ }^{7,8}$ Considering the maternal and fetal risks associated, the obstetrician team decided to admit the pregnant women for hospital surveillance and fetal lung maturation. At 33 weeks of gestation, abundant vaginal bleeding occurred, which led to an emergency cesarean section. The newborn was born perfectly well. The mother had mild anemia 48 hours after delivery ( $\mathrm{Hb} 10.1 \mathrm{~g} / \mathrm{dL}$ ) and was treated with oral iron supplementation. Both mother (after 3 days) and baby (after 16 days) were discharged without further complications. The anatomopathological study confirmed the diagnosis of a type 2 vasa previa.

Through this case, it is possible to understand the crucial importance of a timely diagnosis of vasa previa. If we had not made this diagnosis antenatally, our patient wouldn't have been under our close surveillance in the hospital, and the decision for an emergency cesarean section would not have been made so promptly. Because fetal bleeding and death can occur within minutes, any delay in managing this situation would be fatal.

In conclusion, the antenatal screening of vasa previa applying transvaginal ultrasound and color Doppler technology
DOI https://doi.org/ $10.1055 / \mathrm{s}-0040-1713914$ ISSN $0100-7203$.
Copyright ( 2020 by Thieme Revinter Publicações Ltda, Rio de Janeiro, Brazil
License terms

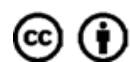




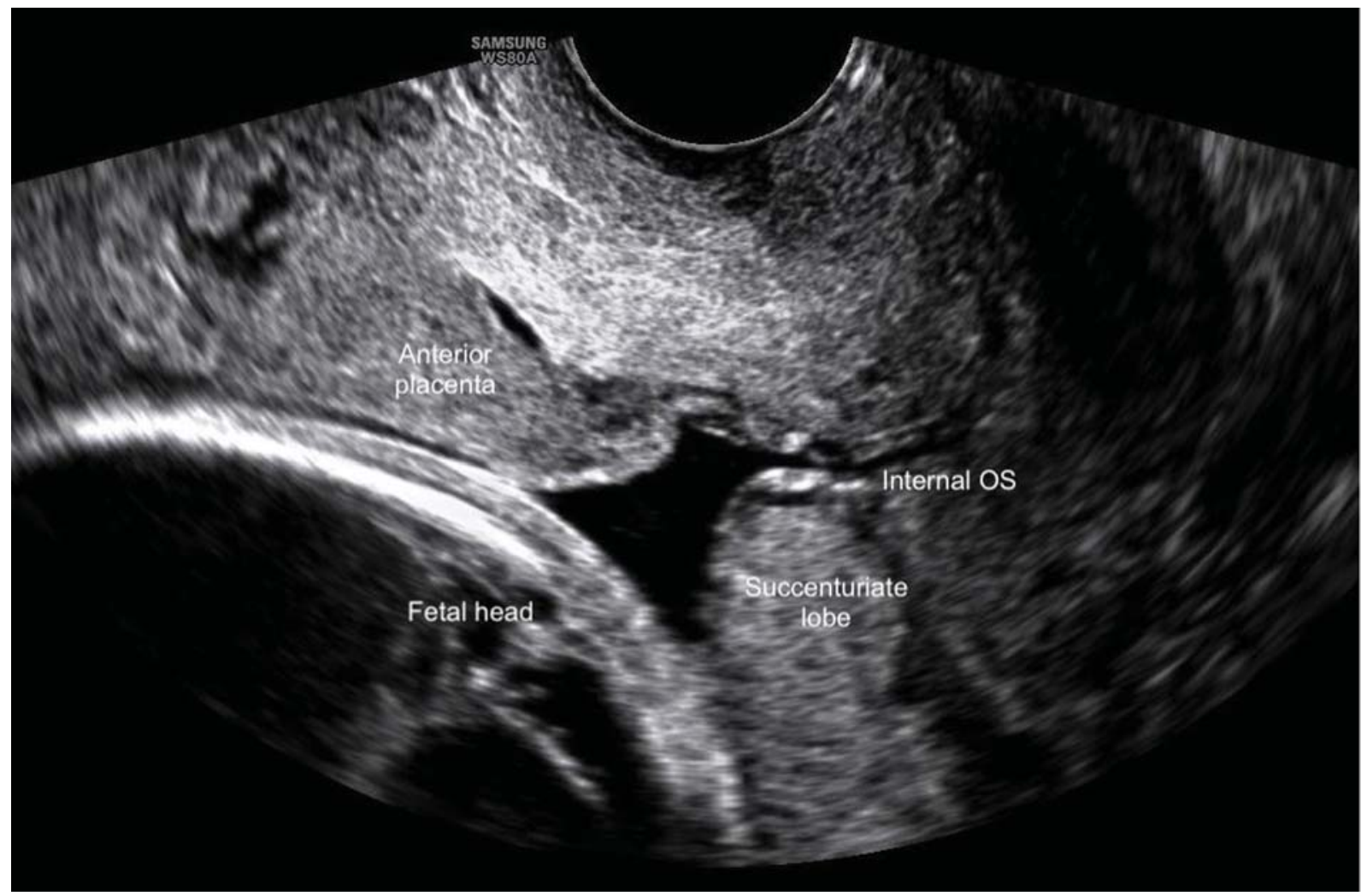

Fig. 1 Sagittal section of the cervix, through transvaginal ultrasound, revealing an anterior low-lying placenta and a posterior succenturiate lobe.

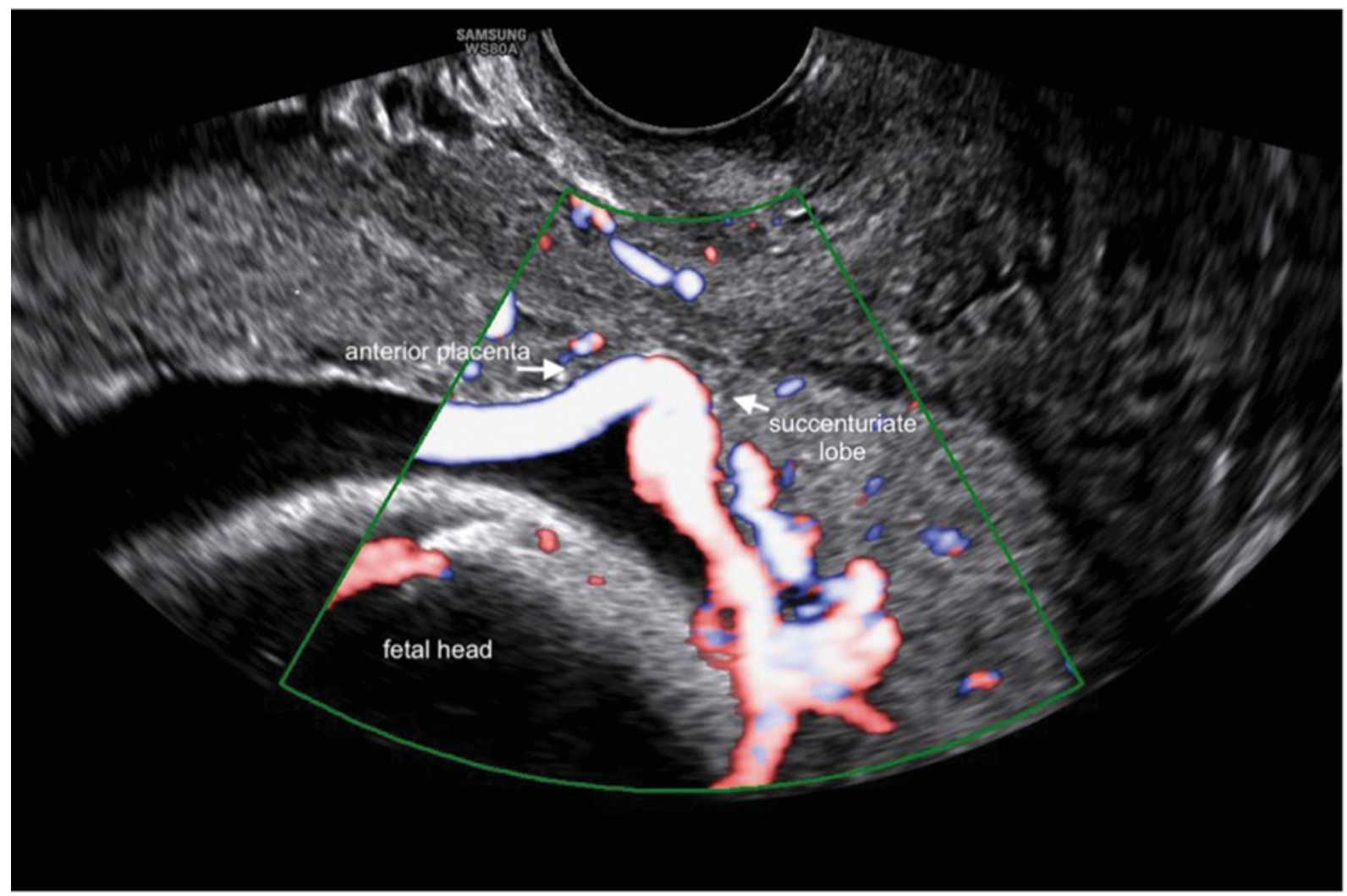

Fig. 2 Use of color Doppler allowed the visualization of a vascular structure (vasa previa) that crosses the internal orifice of the cervix, connecting the separate succenturiate lobe to the main portion of the placenta. The arrows indicate the placental limits of both lobules closest to the internal os. 
510 An Easy to Miss, but Preventable Tragedy Carvalho et al.

during the obstetrical ultrasound is imperative, especially in cases in which some risk factor is recognized.

\section{Conflict of Interests}

The authors have no conflict of interests to declare.

\section{References}

1 Datta S, Babu KM, Mitra S, Patil D. Vasa previa: an avoidable obstetric tragedy. J Obstet Gynaecol India. 2016;66(03):185-187. Doi: 10.1007/s13224-015-0751-4

2 Melcer Y, Maymon R, Jauniaux E. Vasa previa: prenatal diagnosis and management. Curr Opin Obstet Gynecol. 2018;30(06): 385-391. Doi: $10.1097 / G C 0.0000000000000478$

3 Krief D, Naepels P, Chevreau J. Per labor Vasa Previa discovery: A simple clinical diagnosis. Eur J Obstet Gynecol Reprod Biol. 2018; 231:284-285. Doi: 10.1016/j.ejogrb.2018.10.056
4 Swank ML, Garite TJ, Maurel K, Das A, Perlow JH, Combs CA, et al; Obstetrix Collaborative Research Network. Vasa previa: diagnosis and management. Am J Obstet Gynecol. 2016;215(02):223. e1-223.e6. Doi: 10.1016/j.ajog.2016.02.044

5 Ruiter L, Kok N, Limpens J, Derks JB, de Graaf IM, Mol BWJ, Pajkrt E. Systematic review of accuracy of ultrasound in the diagnosis of vasa previa. Ultrasound Obstet Gynecol. 2015;45(05):516-522. Doi: $10.1002 /$ uog. 14752

6 Kajimoto E, Matsuzaki S, Matsuzaki S, Tanaka Y, Kinugasa-Taniguchi Y, Mimura T, et al. Challenges in diagnosis of pseudo vasa previa. Case Rep Obstet Gynecol. 2014;2014:903920. Doi: 10.1155/2014/903920

7 Maymon R, Melcer Y, Tovbin J, Pekar-Zlotin M, Smorgick N, Jauniaux $\mathrm{E}$. The rate of cervical length shortening in the management of vasa previa. J Ultrasound Med. 2018;37(03):717-723. Doi: $10.1002 /$ jum. 14411

8 Oyelese Y, Smulian JC. Placenta previa, placenta accreta, and vasa previa. Obstet Gynecol. 2006;107(04):927-941. Doi: 10.1097/01. AOG.0000207559.15715.98 